\title{
Left ventricular global longitudinal strain in predicting CRT response: one more J-shaped curve in medicine
}

\author{
Michal Orszulak ${ }^{1}$ (1) $\cdot$ Artur Filipecki $^{1} \cdot$ Wojciech Wrobel ${ }^{1} \cdot$ Adrianna Berger-Kucza $^{1} \cdot$ Witold Orszulak $^{1}$. \\ Dagmara Urbanczyk-Swic ${ }^{1}$ - Wojciech Kwasniewski ${ }^{1} \cdot$ Katarzyna Mizia-Stec $^{1}$
}

Received: 8 August 2020 / Accepted: 8 January 2021 / Published online: 6 February 2021

(c) The Author(s) 2021

\begin{abstract}
The aim of the study was: (1) to verify the hypothesis that left ventricular global longitudinal strain (LVGLS) may be of additive prognostic value in prediction CRT response and (2) to obtain such a LVGLS value that in the best optimal way enables to characterize potential CRT responders. Forty-nine HF patients (age $66.5 \pm 10$ years, LVEF 24.9 $\pm 6.4 \%$, LBBB $71.4 \%, 57.1 \%$ ischemic aetiology of HF) underwent CRT implantation. Transthoracic echocardiography was performed prior to and $15 \pm 7$ months after CRT implantation. Speckle-tracking echocardiography was performed to assess longitudinal left ventricular function as LVGLS. The response to CRT was defined as a $\geq 15 \%$ reduction in the left ventricular end-systolic volume ( $\triangle$ LVESV). Thirty-six $(73.5 \%)$ patients responded to CRT. There was no linear correlation between baseline LVGLS and $\triangle$ LVESV $(r=0.09 ; p=0.56)$. The patients were divided according to the percentile of baseline LVGLS: above 80th percentile; between 80 and 40th percentile; below 40th percentile. Two peripheral groups (above 80th and below 40th percentile) formed "peripheral LVGLS" and the middle group was called "mid-range LVGLS". The absolute LVGLS cutoff values were $-6.07 \%$ (40th percentile) and - 8.67\% (80th percentile). For the group of 20 (40.8\%) "mid-range LVGLS" patients mean $\triangle$ LVESV was $33.3 \pm 16.9 \%$ while for "peripheral LVGLS" $\Delta$ LVESV was $16.2 \pm 18.8 \%(p<0.001)$. Among non-ischemic HF etiology, all "mid-range LVGLS" patients (100\%) responded positively to CRT (in "peripheral LVGLS" - 55\% responders; $p=0.015$ ). Baseline LVGLS may have a potential prognostic value in prediction CRT response with relationship of inverted J-shaped pattern. "Mid-range LVGLS" values should help to select CRT responders, especially in non-ischemic HF etiology patients.
\end{abstract}

Keywords CRT · Left Ventricular Global Longitudinal Strain · LVEF · Heart failure

\section{Introduction}

Cardiac resynchronization therapy (CRT) is approved form of treatment for patients with heart failure with reduced ejection fraction (HFrEF) and prolonged QRS duration [1,2]. Identification of 'responders' and 'nonresponders' before CRT implantation is still the essence of the matter and up to $40 \%$ of patients do not benefit after CRT implantation [3].

Michal Orszulak and Artur Filipecki contributed equally to this manuscript.

Michal Orszulak

orszul@vp.pl

1 First Department of Cardiology, School of Medicine in Katowice, Medical University of Silesia, ul Ziolowa 45/47, 40-635 Katowice, Poland
The incidence of non-responders remains the same for many years despite the numbers of trials and great effort that have been dedicated to improve the identification of responders. Dyssynchrony has been thought to be the missing link. Unfortunately, to date, all the approaches have turned out to be suboptimal in this regard [4].

Therefore, we hypothesized that factors other than dyssynchrony may contribute to CRT response. Strain constitutes a sensitive method for quantifying global left ventricular function [5] and can provide prognostic information beyond routine LVEF [6]. Echocardiographic strain by speckle-tracking precisely characterizes left ventricle performance [7], scar burden [8], and dyssynchrony [9]. Left ventricle global longitudinal strain (LVGLS) is associated with the outcome in general population [10] as well as in heart failure patients [11]. Previous studies have demonstrated that baseline left ventricle function stays in relation 
with final reverse remodeling. In one report from a post hoc analysis of the randomized control MADIT-CRT trial, LV functional improvement as assessed by $\triangle$ LVGLS was powerfully linked to an improved outcome on top of $\triangle \mathrm{LVEF}$ or CRT response assessed by $\triangle$ LVESV [12]. Advantages of strain assessment include obtainable in most of cases and higher reproducibility than LVEF $[13,14]$.

The main goals were to verify if LVGLS may be of additive prognostic value in CRT response prediction and to obtain such a LVGLS value that in the best possible way enables to characterize potential CRT responders.

\section{Materials and methods}

\section{Population}

The prospective study included 49 patients ( $84 \%$ male, $66.5 \pm 10$ years, $34.7 \% / 63.3 \%$ in New York Heart Association class II/III) with symptomatic heart failure who met the criteria for CRT implantation in class I/IIa according to the 2013 ESC guidelines [15]. Exclusion criteria were acute coronary syndrome for three months, inadequate CRT delivery after follow-up (BiV pacing rate $<90 \%$ ) or the poor image quality of the echocardiography.

Primarily, consecutive 71 patients were enrolled into the study. Six patients were excluded due to poor echocardiographic windows, four patients were excluded because of suboptimal pace delivery ( $\mathrm{BiV}<90 \%)$ during follow-up, four patients were lost during follow-up, four patients declined to participate in the study, two patients were excluded due to dysfunction of CRT (dislocation of LV lead), and 2 patients died during follow-up. The remaining 49 patients formed a study group.

Twenty (40.8\%) patients had already had a cardiac implantable electronic device (CIED) and received an upgrade to a resynchronization system, while the others (29 patients, 59.2\%) received a CRT de novo. Almost all the devices had a defibrillator capability (CRT-D) and the LV was preferably placed in either the lateral or the posterolateral vein. Patients were receiving optimal pharmacological therapy.

All the patients were informed and signed a written consent. The study protocol was approved by the local bioethical committee.

\section{Follow-up}

Patients were evaluated in one-year and long-term follow-up.

In the 1-year follow-up, a clinical status and transthoracic echocardiography were assessed; the response to CRT ("responder") was defined in the short-term follow-up as a $\geq 15 \%$ LVESV reduction.
In the long-term follow-up, the prognostic value of the results was verified. Outcome was defined as an all-cause mortality. Vital status or information about death date were extracted from medical reports or received from patients' relatives. Status was ascertained in December 2020.

\section{Echocardiography}

Standard transthoracic 2D echocardiography was performed by an experienced echocardiographer using a cardiovascular ultrasound system (Vivid 7, GE Medical Systems) before and 15 months after CRT implantation. LV end-systolic volume (LVESV), end-diastolic volume (LVEDV), and LVEF were measured using the biplane Simpson method. LVGLS measurements were performed to assess the global left ventricular function.

All the measurements were performed in three representative cardiac cycles and then averaged. Echocardiographic recordings were analyzed blinded to clinical data. Image analysis was performed offline using a customized software package (EchoPac). The response to CRT was defined as $\mathrm{a} \geq 15 \%$ LVESV reduction.

\section{LVGLS measurements}

By two-dimensional speckle-tracking echocardiography, longitudinal strain values were obtained from three apical views with frame rates $>40 \mathrm{~Hz}$. Longitudinal strain values were computed after determining aortic valve closure (AVC). AVC was determined from pulsed-wave Doppler of the LV outflow tract and was superimposed on the strain waveforms. Automatic tracking of the endocardial contour on an end-systolic frame was carefully verified. The regions of interest (ROI) were manually adjusted to be in accordance with the actual thickness of myocardium and to ensure optimal tracking. The software automatically divided myocardium into 18 segments. Strain values and the longitudinal time-strain curves for all 18 segments were computed. LVGLS was calculated as an average from the 18 segmental strain values from the three apical views.

\section{Statistical analysis}

Statistical analysis was performed using Statistica 10 Software. Distribution was verified using the Shapiro-Wilk test. Continuous variables are expressed as the mean \pm standard deviation and were compared using $U$-Mann test or Wilcoxon test or Kruskal-Wallis test when appropriate. Categorical variables (reported as numbers with percentages) were tested using $\chi^{2}$ statistics. Spearman rank coefficient tests were used to determine the relationships between the variables. For survival analysis, Kaplan-Meier curve with testing using log-rank statistics was performed. Reproducibility 
was assessed for strain measurements. Twenty studies were reanalyzed by the same and other observer to assess intraand inter-observer variabilities. $p$ value $<0.05$ was considered to be statistically significant.

\section{Results}

\section{Baseline characteristics}

The study included a total of 49 patients (84\% male, $66.5 \pm 10$ years, NYHA II/III/IV: $34.7 \% / 63.3 \% / 2 \% ; 57.1 \%$ ischemic aetiology of HF), who underwent CRT implantation. The mean QRS duration was $173.1 \pm 19.1 \mathrm{~ms}$. Thirty-five $(71.4 \%)$ patients had a native LBBB according to conventional ECG criteria, seven (14.3\%) patients had a dominant right ventricular pacing rhythm, and seven patients had non-LBBB. The baseline characteristics are presented in Table 1. Thirty-six (73.5\%) patients were CRT responders ( $\geq 15 \%$ reduction in LVESV) and 13 (26.5\%) non-responders. There were no significant differences in the baseline demographics, clinical or echocardiographic parameters between responders and non-responders.

The inter- and intra-observer variabilities for the LVGLS were 7 and 5\%, respectively.

\section{One-year follow-up}

The mean follow-up was $14.9 \pm 7$ months. Overall, NYHA class decreased from $2.8 \pm 0.5$ to $1.9 \pm 0.7(p<0.001)$. During the follow-up, almost all the echocardiographic parameters improved. The LVEDV and LVESV volumes were reduced (from $282 \pm 129 \mathrm{ml}$ to $238 \pm 120 \mathrm{ml}$ and from $218 \pm 109 \mathrm{ml}$ to $166 \pm 98 \mathrm{ml}$, respectively; $p<0.001$ for both). The LVEF increased from $25.9 \pm 6 \%$ to $32 \pm 79 \%$; $p<0.001$. For the entire population, CRT led to significant increase of LVGLS: $-6.94 \pm 2.16$ to $-7.95 \pm 2.68 \%$; $p=0.039$. Improvements in the echocardiographic parameters (LVESV, LVEDV, LVEF, and strain values) concerned mainly responders while in non-responders no significant changes were observed after CRT implantation.

\section{LVGLS and CRT response}

There was no linear correlation between baseline LVGLS and $\triangle \mathrm{LVESV}(r=0.09 ; p=0.56)$. We have found significant association between $\triangle \mathrm{LVESV}$ and improvement in LV performance expressed by $\Delta$ LVGLS $(r=0.32 ; p=0.028)$.

\section{LVGLS in prediction of CRT response}

Correlation between baseline LVGLS and $\triangle$ LVESV was not linear ( $r=0.09 ; p=0.56)$ but it has turned out to be an inverted J-shaped curve (Fig. 1a). We sought that patients with LVGLS values corresponding to the peak of the curve might have greater chance to CRT response than the patients with the most extreme LVGLS values. Therefore, the study group was categorized into two groups: patients with middle LVGLS values (so-called "mid-range LVGLS") and extreme LVGLS values (so-called "peripheral LVGLS") (Fig. 2).

Groups were formed according to the percentile of baseline LVGLS values. Few LVGLS percentile cutoff threshold were verified (Table 2) to select the most potent CRT recipient (based on $\triangle \mathrm{LVESV}$ ). The best cutoff percentile LVGLS values were obtained for 40th percentile (absolute LVGLS - 6.07\%) and 80th percentile (absolute LVGLS $-8.67 \%$ ). Detailed characteristics of the groups are presented in Table 3. Finally, patients with LVGLS values above 80th and below 40th percentile formed "peripheral LVGLS" while patients with LVGLS values between 80 and
Table 1 Baseline characteristics of general population, responders, and non-responders

\begin{tabular}{llll}
\hline & Study population $(n=49)$ & Responders $(n=36)$ & Non-responders $(n=13)$ \\
\hline Age (years) & $67 \pm 10$ & $68 \pm 10$ & $63 \pm 10$ \\
Male sex, $n(\%)$ & $41(84)$ & $30(83.3)$ & $11(84.6)$ \\
NYHA functional class & $2.8 \pm 0.5$ & $2.8 \pm 0.6$ & $2.7 \pm 0.4$ \\
Baseline NYHA class III, $n(\%)$ & $31(63.3)$ & $21(58.3)$ & $10(76.9)$ \\
Ischemic etiology of HF, $n(\%)$ & $28(57.1)$ & $20(55.6)$ & $8(61.5)$ \\
QRS (ms) & $173 \pm 19$ & $173 \pm 21$ & $174 \pm 16$ \\
LBBB, $n(\%)$ & $35(71.4)$ & $27(75)$ & $8(61.5)$ \\
AF at implantation, $n(\%)$ & $7(14.3)$ & $6(16.7)$ & $1(7.7)$ \\
CIED before CRT $(=$ upgrade & $20(40.8)$ & $11(30.6)$ & $9(69.2)$ \\
$\quad$ to CRT), $n(\%) *$ & & \\
LVESV (ml) & $218 \pm 109$ & $217 \pm 107$ & $223 \pm 119$ \\
LVEF $(\%)$ & $25 \pm 6$ & $24 \pm 6$ & $27 \pm 7$ \\
LVGLS & $-6.94 \pm 2.16$ & $-6.75 \pm 1.65$ & $-7.48 \pm 3.19$ \\
\hline
\end{tabular}

$*_{p}<0.05$ responders vs. non-responders 

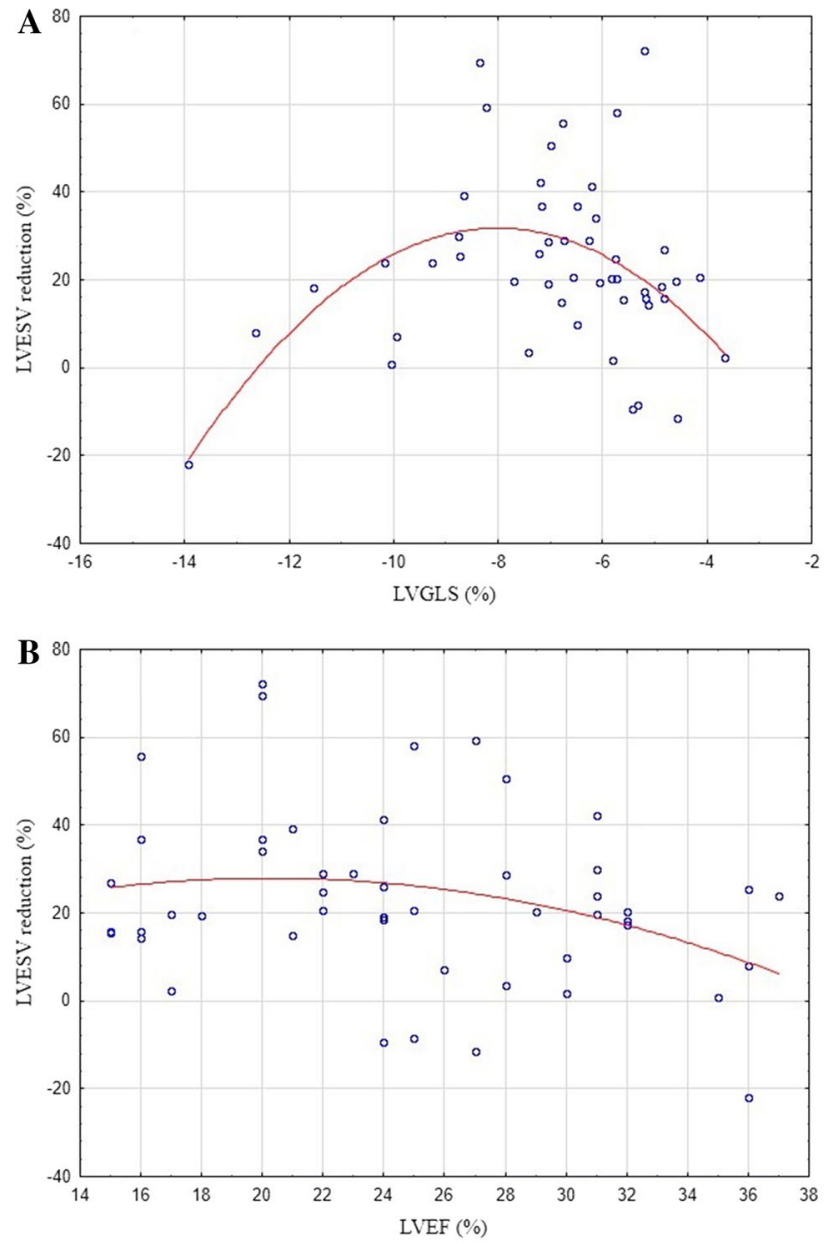

Fig. 1 Relationship between $\triangle \mathrm{LVESV}$ and baseline LV function assessed by LVGLS (a) and LVEF (b)

40th percentile formed "mid-range LVGLS". Characteristics of both groups are shown in Table 4. For "mid-range
LVGLS" mean $\triangle$ LVESV was $33.3 \pm 16.9 \%$ and for "peripheral LVGLS" $16.2 \pm 18.8 \%$. This difference was statistically significant ( $p=0.00056$ ) (Fig. 3). Baseline LVEF did not differ between groups: "mid-range LVGLS" $24 \pm 4.5 \%$ vs. "peripheral LVGLS" 25.6 $\pm 7.4 \% ; p=0.4$. After follow-up period, increase of LVEF ( $\triangle \mathrm{LVEF})$ was greater in "midrange LVGLS" than in "peripheral LVGLS" group (absolute $\Delta$ LVEF $11.2 \pm 6.2 \%$ vs. $4.1 \pm 8.2 \% ; p=0.0008$; percentage $\Delta$ LVEF $151.3 \%$ vs. $124.4 \% ; p=0.0048)$. Therefore, final LVEF was higher in mid-range group than in peripheral group (35.1\% vs. $29.7 \%$; $p=0.0025)$.

Prediction of CRT response based on LVGLS values was particularly powerful in patients with non-ischemic HF etiology. In patients with non-ischemic etiology of HF, all "midrange LVGLS" patients responded to CRT while among "peripheral LVGLS" there were 54.5\% (6/11 patients) responders ( $p=0.015$; with Yates's correction $p=0.0537)$. In patients with ischemic HF etiology, there was no difference in incidence of CRT responders between "peripheral LVGLS" and "mid-range LVGLS" ( $p=0.9$ ) (Fig. 4).

\section{Long-term follow-up}

The mean long-term follow-up was 2009 days (335-2808 days). During the long-term follow-up, 32 (65.3\%) patients survived (one patient underwent heart transplantation) and 17 (34.7\%) patients died. Comparison of the clinical and echocardiography data revealed significantly higher reduction of LVESV in survivals as compared to nonsurvivals obtained after the one-year follow-up $(28.3 \pm 17.5$ vs. $14.4 \pm 20.9 \mathrm{ml} ; p<0.025)$. We did not observe any significant differences in other parameters. The Kaplan-Meier curves for all-cause mortality were calculated for the following categories: (a) responders and non-responders (log-rank
Fig. 2 Inverted J-shaped curve relationship between baseline LVGLS and $\triangle$ LVESV. Schematic presentation of how study population was divided on "peripheral LVGLS" and "midrange LVGLS" according to the percentile of baseline LVGLS

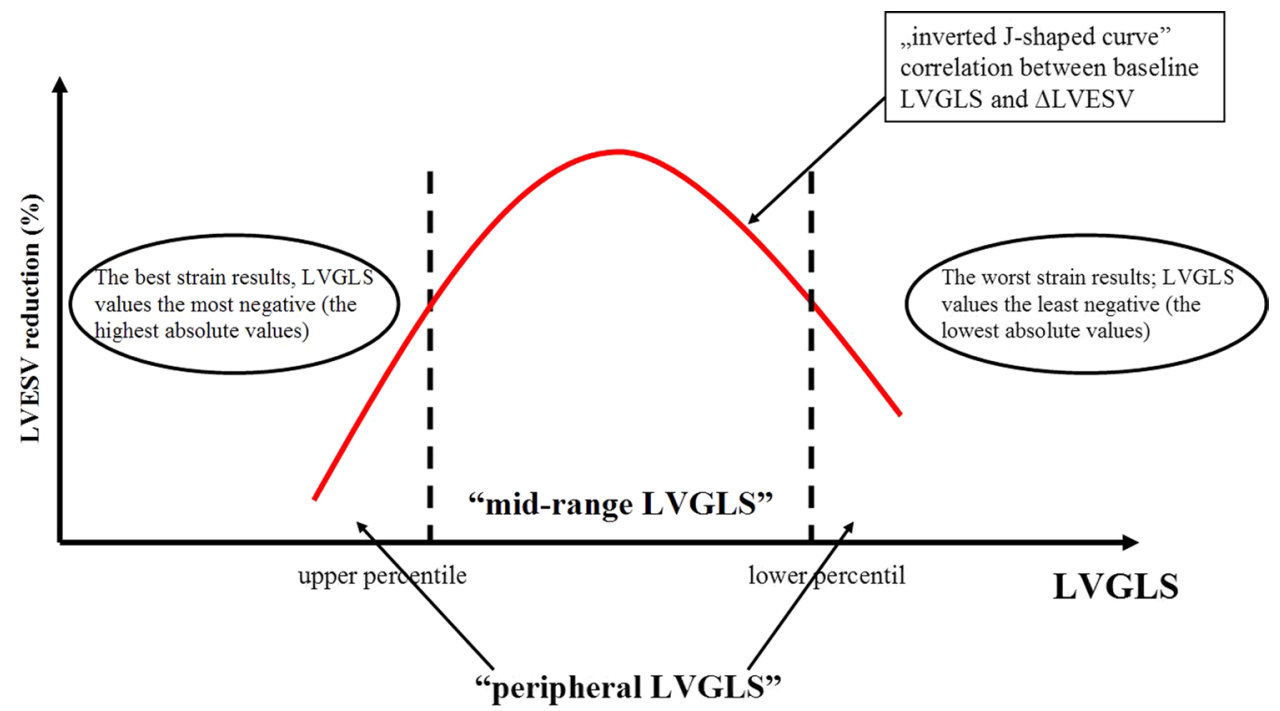


Table $2 \quad \triangle$ LVESV in each groups of patients divided according to different LVGLS percentile cutoff threshold

\begin{tabular}{|c|c|c|c|c|}
\hline $\begin{array}{l}\text { LVGLS percentile cutoff and cor- } \\
\text { responding absolute LVGLS }\end{array}$ & $\begin{array}{l}\text { Group A (the worst } \\
\text { LVGLS values) }\end{array}$ & $\begin{array}{l}\text { Group B ("mid-range } \\
\text { LVGLS") }\end{array}$ & $\begin{array}{l}\text { Group C (the best } \\
\text { LVGLS values) }\end{array}$ & $p$ value \\
\hline $\begin{array}{l}P_{60}=-7 \% \\
P_{20}=-5.2 \%\end{array}$ & $\begin{array}{l}19.3 \pm 20.4 \% \\
(n=11)\end{array}$ & $\begin{array}{l}24.4 \pm 19.1 \% \\
(n=19)\end{array}$ & $\begin{array}{l}24.2 \pm 20.8 \% \\
(n=19)\end{array}$ & $\begin{array}{l}\text { A vs. } \mathrm{B} \rightarrow p=0.27 \\
\text { A vs. } \mathrm{C} \rightarrow p=0.22 \\
\mathrm{~B} \text { vs. } \mathrm{C} \rightarrow p=1 \\
\mathrm{~B} \text { vs. }(\mathrm{A}+\mathrm{C}) \rightarrow p=0.59\end{array}$ \\
\hline $\begin{array}{l}P_{75}=-5.43 \% \\
P_{25}=-7.7 \%\end{array}$ & $\begin{array}{l}14.9 \pm 21.4 \% \\
(n=13)\end{array}$ & $\begin{array}{l}27.4 \pm 14.9 \% \\
(n=24)\end{array}$ & $\begin{array}{l}23.6 \pm 24.9 \% \\
(n=12)\end{array}$ & $\begin{array}{l}\text { A vs. } \mathrm{B} \rightarrow p=0.014 \\
\text { A vs. } \mathrm{C} \rightarrow p=0.25 \\
\mathrm{~B} \text { vs. } \mathrm{C} \rightarrow p=0.56 \\
\text { B vs. }(\mathrm{A}+\mathrm{C}) \rightarrow p=0.058\end{array}$ \\
\hline $\begin{array}{l}P_{66}=-7.17 \% \\
P_{33}=-5.76 \%\end{array}$ & $\begin{array}{l}18.4 \pm 21.4 \% \\
(n=17)\end{array}$ & $\begin{array}{l}28 \pm 14.4 \% \\
(n=16)\end{array}$ & $\begin{array}{l}23.4 \pm 22.5 \% \\
(n=16)\end{array}$ & $\begin{array}{l}\text { A vs. } \mathrm{B} \rightarrow p=0.053 \\
\text { A vs. } \mathrm{C} \rightarrow p=0.29 \\
\mathrm{~B} \text { vs. } \mathrm{C} \rightarrow p=0.47 \\
\text { B vs. }(\mathrm{A}+\mathrm{C}) \rightarrow p=0.12\end{array}$ \\
\hline $\begin{array}{l}P_{80}=-8.67 \% \\
P_{40}=-6.07 \%\end{array}$ & $\begin{array}{l}17.7 \pm 19.9 \% \\
(n=20)\end{array}$ & $\begin{array}{l}33.3 \pm 16.9 \% \\
(n=20)\end{array}$ & $\begin{array}{l}12.8 \pm 16.3 \% \\
(n=9)\end{array}$ & $\begin{array}{l}\text { A vs. } \mathrm{B} \rightarrow p=0.029 \\
\text { A vs. } \mathrm{C} \rightarrow p=1 \\
\mathrm{~B} \text { vs. } \mathrm{C} \rightarrow p=0.06 \\
\text { B vs. }(\mathbf{A}+\mathbf{C}) \rightarrow \mathbf{p}=\mathbf{0 . 0 0 0 5}\end{array}$ \\
\hline
\end{tabular}

Table 3 Comparison of the groups according to 80th and 40th percentile of baseline LVGLS value

\begin{tabular}{|c|c|c|c|c|}
\hline & $\begin{array}{l}\text { A The worst LVGLS (below } \\
\text { 40th percentile) } n=20\end{array}$ & $\begin{array}{l}\text { B "mid-range LVGLS" (between } 80 \\
\text { and 40th percentile) } n=20\end{array}$ & $\begin{array}{l}\text { C The best LVGLS (above } \\
\text { 80th percentile) } n=9\end{array}$ & $p$ value \\
\hline \multicolumn{5}{|l|}{ BASELINE } \\
\hline Age (years) & $64.8 \pm 10.7$ & $65.2 \pm 11$ & $73.2 \pm 4.5$ & $0.047^{\#}$ \\
\hline Baseline LVGLS & $-5.2 \pm 0.6$ & $-7.1 \pm 0.7$ & $-10.6 \pm 1.8$ & $<0.001^{\#}$ \\
\hline Male sex, $n(\%)$ & $17(85)$ & $17(85)$ & $7(78)$ & $0.87 *$ \\
\hline NYHA functional class & $2.9 \pm 0.5$ & $2.6 \pm 0.5$ & $2.9 \pm 0.4$ & $0.24^{\#}$ \\
\hline Ischemic HF etiology, $n(\%)$ & $11(55)$ & $11(55)$ & $6(67)$ & $0.82 *$ \\
\hline QRS (ms) & $178 \pm 17.2$ & $169.7 \pm 20.2$ & $168.1 \pm 23$ & $0.33^{\#}$ \\
\hline $\mathrm{LBBB}, n(\%)$ & $17(85)$ & $13(65)$ & $5(56)$ & $0.19^{*}$ \\
\hline LVEDV (ml) & $354.2 \pm 157.6$ & $252.7 \pm 73.7$ & $188.8 \pm 56.8$ & $<0.001 \#$ \\
\hline LVESV (ml) & $276.7 \pm 133.3$ & $198.1 \pm 64.5$ & $133.2 \pm 38.8$ & $<0.001 \#$ \\
\hline $\operatorname{LVEF}(\%)$ & $22.1 \pm 5.9$ & $24 \pm 4.5$ & $33.3 \pm 3.6$ & $<0.001 \#$ \\
\hline \multicolumn{5}{|l|}{ AFTER CRT } \\
\hline $\operatorname{LVEF}(\%)$ & $27.3 \pm 6.3$ & $35.1 \pm 5$ & $35 \pm 6.5$ & $<0.001^{\#}$ \\
\hline$\triangle \operatorname{LVESV}(\%)$ & $17.7 \pm 20$ & $33.3 \pm 16.9$ & $12.8 \pm 16.3$ & $0.006^{\#}$ \\
\hline$\triangle \mathrm{LVEF}$ (absolute value) & $5.2 \pm 8.5$ & $11.2 \pm 6.2$ & $1.7 \pm 7.3$ & $0.003^{\#}$ \\
\hline$\triangle \mathrm{LVEF}$ (percentage value) & $32.7 \pm 49.1$ & $51.3 \pm 33.8$ & $6 \pm 22.4$ & $0.033^{\#}$ \\
\hline$\triangle \mathrm{NYHA}$ & $0.95 \pm 0.74$ & $0.75 \pm 0.94$ & $0.83 \pm 0.71$ & $0.79^{\#}$ \\
\hline$\Delta$ LVGLS (absolute value) & $-1.7 \pm 2$ & $-1.1 \pm 2.7$ & $1.1 \pm 3.6$ & $0.08 \#$ \\
\hline$\Delta$ LVGLS (percentage value) & $136.9 \pm 51.5$ & $116.6 \pm 39.2$ & $91.7 \pm 36.1$ & $0.047 \#$ \\
\hline
\end{tabular}

$* \chi^{2}$ test for A vs. B vs. C

\#Kruskal-Wallis test for A vs. B vs. C

$p=0.0025$ ) (Fig. 5a); (b) "peripheral LVGLS" and "mid- Discussion range LVGLS” (log-rank $p=0.397)$ (Fig. 5b).
In this study, we intended to provide novel data concerning LV systolic function expressed as LVGLS, in the context of CRT. The main finding of the study is that baseline LVGLS may have a potential prognostic value 
Table 4 Comparison of "mid-range LVGLS" and "peripheral LVGLS": before CRT implantation and after follow-up period

\begin{tabular}{|c|c|c|c|}
\hline & $\begin{array}{l}\text { "mid-range } \\
\text { LVGLS" } \\
n=20\end{array}$ & $\begin{array}{l}\text { "peripheral } \\
\text { LVGLS" } \\
n=29\end{array}$ & $p$ value \\
\hline \multicolumn{4}{|l|}{ Baseline } \\
\hline Age (years) & $65 \pm 11$ & $67 \pm 10$ & 0.37 \\
\hline Male sex, $n(\%)$ & $17(85)$ & $24(83)$ & 0.83 \\
\hline NYHA functional class & $2.6 \pm 0.5$ & $2.9 \pm 0.5$ & 0.12 \\
\hline Ischemic HF etiology, $n(\%)$ & $11(55)$ & $17(58.6)$ & 0.8 \\
\hline QRS (ms) & $169.7 \pm 20.2$ & $175.2 \pm 19.1$ & 0.34 \\
\hline $\mathrm{LBBB}, n(\%)$ & $13(65)$ & $22(75.9)$ & 0.41 \\
\hline LVEDV (ml) & $252 \pm 74$ & $302 \pm 154$ & 0.33 \\
\hline LVESV (ml) & $198 \pm 65$ & $232 \pm 131$ & 0.47 \\
\hline $\operatorname{LVEF}(\%)$ & $24 \pm 4.5$ & $25.6 \pm 7.4$ & 0.4 \\
\hline \multicolumn{4}{|l|}{ After CRT } \\
\hline LVEDV (ml) & $198 \pm 66$ & $265 \pm 141$ & 0.07 \\
\hline $\operatorname{LVESV}(\mathrm{ml})$ & $129 \pm 46$ & $192 \pm 115$ & 0.03 \\
\hline $\operatorname{LVEF}(\%)$ & $35.1 \pm 5$ & $29.7 \pm 7.2$ & 0.003 \\
\hline$\triangle \operatorname{LVESV}(\%)$ & $33.3 \pm 16.9$ & $16.2 \pm 18.8$ & $<0.001$ \\
\hline$\triangle \mathrm{LVEF}$ (absolute value) & $11.2 \pm 6.2$ & $4.1 \pm 8.2$ & $<0.001$ \\
\hline$\Delta \mathrm{LVEF}$ (percentage value) & $151.3 \pm 33.8$ & $124.4 \pm 44$ & 0.005 \\
\hline$\triangle \mathrm{NYHA}$ & $0.75 \pm 0.9$ & $0.9 \pm 0.7$ & 0.61 \\
\hline$\Delta$ LVGLS (absolute value) & $-1.1 \pm 2.7$ & $-0.8 \pm 2.9$ & 0.99 \\
\hline $\begin{array}{l}\Delta \text { LVGLS (percentage } \\
\text { value) }\end{array}$ & $116.6 \pm 39.2$ & $121.3 \pm 44.8$ & 0.92 \\
\hline
\end{tabular}

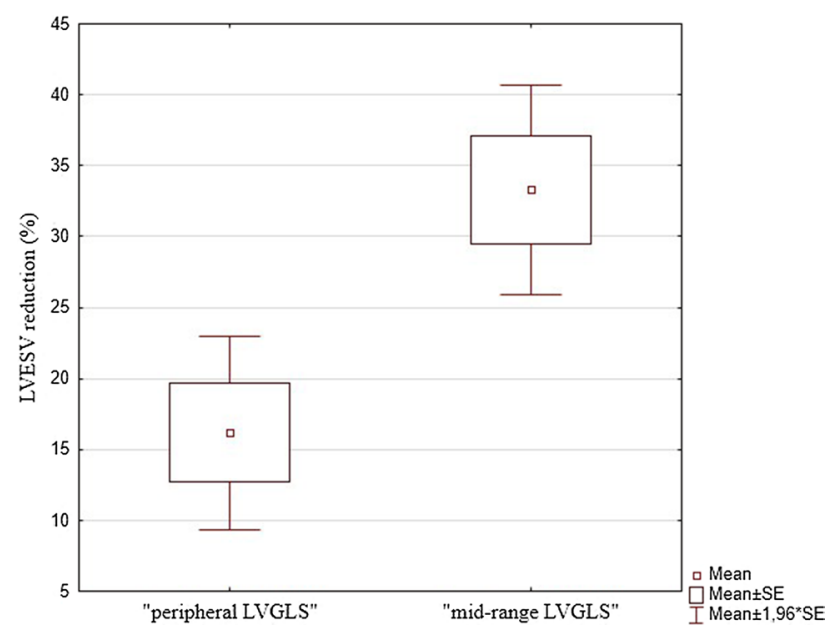

Fig. 3 Mean $\triangle$ LVESV in "peripheral LVGLS" and "mid-range LVGLS"

in prediction CRT response with relationship of inverted J-shaped pattern.

LVGLS by speckle-tracking echocardiography characterizes global and regional LV function, LV scar burden, and myocardial viability. Previous studies showed LVGLS was associated with LV reverse remodeling [16] as well as with long-term outcome after CRT implantation [17]. Hasselberg et al. [18] suggested that CRT response by reverse remodeling may be dependent on improvement of longitudinal function. Gorcsan et al. [19] positively verified LVGLS as additive prognostic value in predicting CRT response. Our novel finding is that "mid-range LVGLS" values enable to select CRT responders, especially in nonischemic HF etiology patients.

\section{Bermuda triangle: LVEF, LVGLS, and LVESV}

We have found strong linear correlation between the baseline values LVGLS and LVEF $(r=0.64 ; p<0.001)$, similar to other researchers [20]. There was no linear correlation between baseline LVGLS/LVEF and $\triangle$ LVESV after CRT ( $r=0.09 ; p=0.56$ and $r=-0.25 ; p=0.08$, respectively). Echocardiographic response ( $\triangle \mathrm{LVESV}$ ) was associated with the improvement of LV performance expressed as $\triangle \mathrm{LVEF}$ $(r=0.6 ; p<0.001)$ and $\Delta$ LVGLS $(r=0.32 ; p=0.028)$. Our results stay in line with the work of Menet et al. [21] who confirmed overmentioned correlations and showed $\triangle$ LVESV as a strong predictor of outcome following CRT.

\section{LVGLS and CRT}

Important prognostic value of echocardiographic myocardial deformation parameters was confirmed in heart failure patients and CRT recipients [11]. Yan Ma and DelgadoMontero showed the ability of LVGLS as alone parameter in predicting positive effects of CRT. Respectively, LVGLS predicted echocardiographic response to CRT [16] and LVGLS was significantly associated with long-term outcome after CRT [17]. In the study [22] with large cohort of CRT patients, baseline LVGLS was independently associated with the combined endpoint. Kydd et al. [23] developed multiparametric predictive score (so-called " $p$-score"), incorporating LVGLS, offering a potential to predict CRT responders. Similar multiparametric echocardiographic score proposed by Park et al., including LVGLS, was helpful in selecting patients likely to undergo reverse remodeling and prediction clinical outcome [24].

Among the achievable studies dealing with longitudinal strain and CRT, final end-point was defined differently (LV reverse remodeling, long-term outcome or occurrence of ventricular arrhythmia) but relation"the better LVGLS, the better prognosis" remains in force. In our study, we have not found straight linear correlation between baseline LVGLS and $\triangle$ LVESV. In "mid-range LVGLS" group mean $\triangle$ LVESV was greater than in the patients with peripheral LVGLS values $(33.3 \pm 16.9 \%$ vs. $16.2 \pm 18.8 \% ; p=0.00056)$. This group of 20 subjects was called "mid-range LVGLS" because among all the patients qualified to CRT implantation 
Fig. 4 Response to CRT in nonischemic/ischemic HF etiology with regard to LVGLS group ("peripheral LVGLS" and "midrange LVGLS")

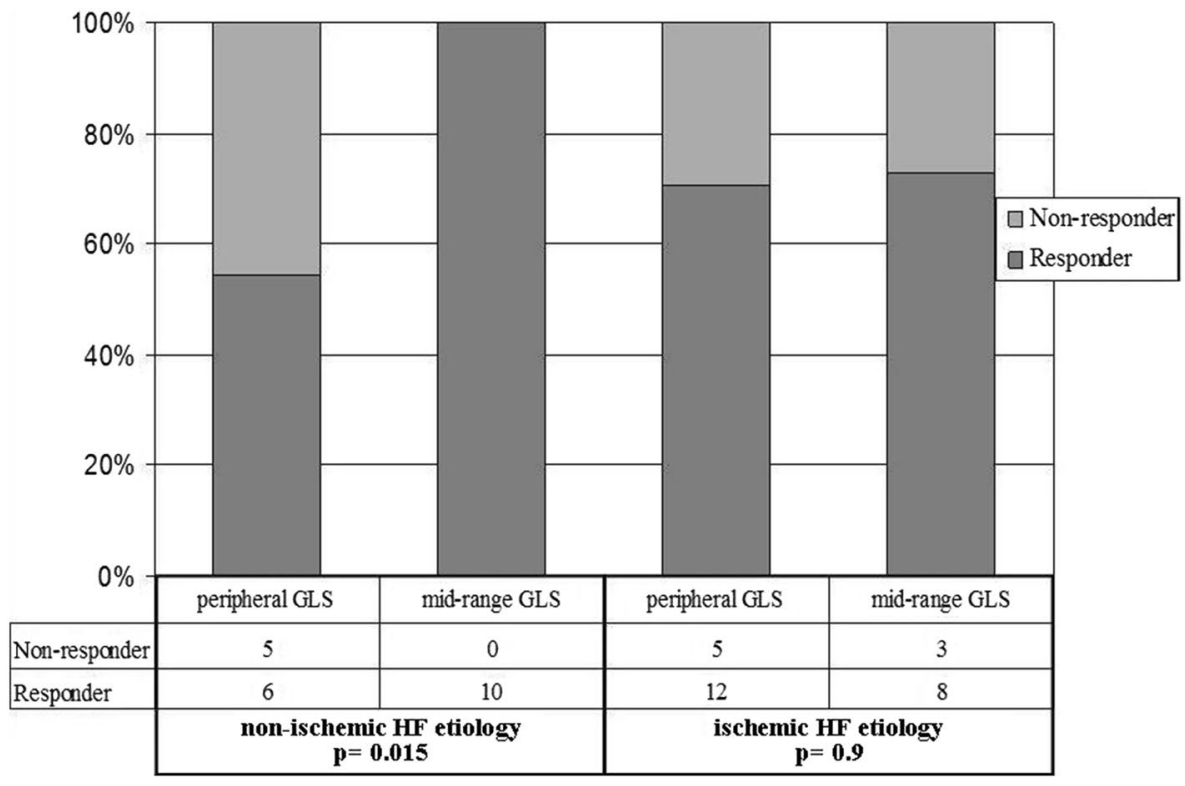

A
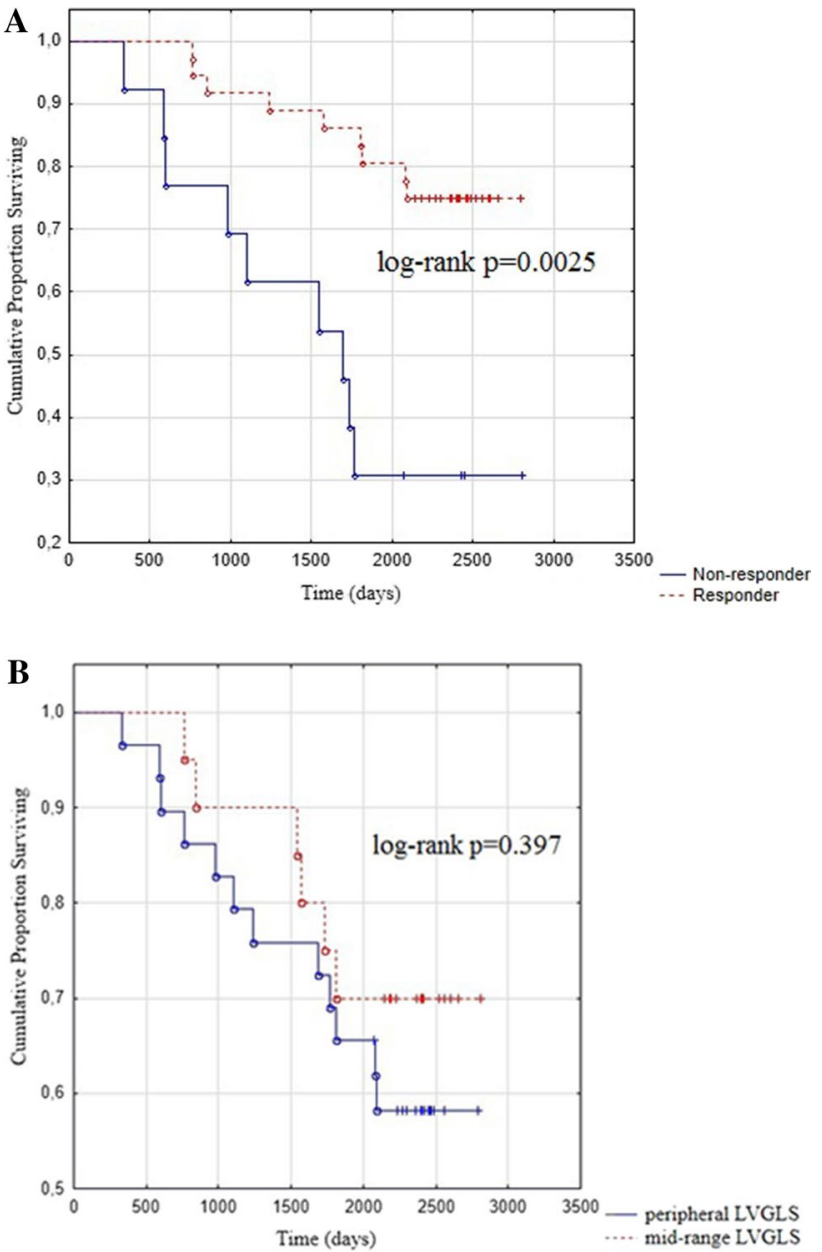

Fig. 5 a Kaplan-Meier curves for all-cause mortality in the longterm follow-up according to category responder vs. non-responder. b Kaplan-Meier curves for all-cause mortality in the long-term follow-up according to category "peripheral LVGLS" and "mid-range LVGLS they had intermediate values of LVGLS. Remaining 29 patients represented extreme LVGLS values (either very good or very poor), therefore, we called this group "peripheral LVGLS". Groups did not differ significantly in terms of demographics, clinical or echocardiographic characteristics.

The present study is the first to the best of our knowledge to evaluate the prognostic value of baseline LVGLS in nonlinear manner. In the previous reports, better strain values were related with CRT benefits. Our results did not confirm the predictive value of LVGLS in this way. Patients with the highest LVGLS values in our study population (above 80th percentile; absolute LVGLS: $<-8.67 \%$ ) reached average LVESV reduction. The shape of correlation line between baseline LVGLS and $\triangle$ LVESV resembles inverted "J-curve". Our findings confirm the previous observations of QRS duration in patients with LBBB, a "U shaped" distribution resulted with non-responders clustered between 120 and $130 \mathrm{~ms}$ and above $180 \mathrm{~ms}$ [25]. Interestingly, for LVEF we were not able to set up comparable layout.

We disclosed non-linear prognostic value of LVGLS. Patients with mid-range baseline LVGLS were likely to benefit more than "peripheral LVGLS" patients. We have not found theoretic explanation of this fact in the literature. It does not seem to be a bias because other parameters and results keep in line with the previous studies, our patients reached comparable improvement in LVEF and LVESV reduction with similar percentage of responders [26], 27].

We have sought theoretical premise for explanation why patients with intermediate LVGLS values benefit the most. In patients with severely impaired systolic function, gain of synchronization will not contribute to overall heart's performance. It seems to be "too late" and extremely decreased 
contractility/viability would not improve even after restoration of electrical dyssynchrony. In patients with better LV function, CRT profits would not be observed due to other reasons. In this group of patients, probability of extreme gain of LV function after restoration of LV synchrony seems lower due to underlying impairment of myocardium. In patients with ischemic cardiomyopathy, presence of scar, inactive part of $\mathrm{LV}$, make unable to complete convalescence [28]. In patients with non-ischemic cardiomyopathy, the probability of CRT profits remains higher but we cannot rule out genetic conditioning which restrains absolute LV systolic function recovery.

The fiber direction of the subendocardial myocardial layer is mainly longitudinally oriented, while the fiber direction in the midmyocardial layer is mainly circular, although all are helically ordered [29]. Loss of longitudinal function from the subendocardial fibers is typical for ischemic damage and may explain why longitudinal function by LVGLS is less improved after CRT in patients with ischemic cardiomyopathy. Longitudinal functional reserve is present in non-ischemic patients, providing better chances for CRT response [18]. These findings support our results with regard to HF etiology.

We can find parallel with clinical condition expressed as NYHA functional class. In both fields, subjects with marginal quantities are less likely to respond favorably to CRT. ESC 2016 guidelines include NYHA class IV to CRT implantation but certain patients may be too sick to realize long-term mortality benefits from CRT [30]. Recent findings of Cimino et al. [31] suggest that end-stage HF patients, presenting before CRT with LVEF $<22.15 \%$, may not benefit from the procedure after 6 months. On the other hand in NYHA class I, mortality benefit and symptom improvement [32] from CRT have not been demonstrated. Moreover, CRT might be harmful, in the European REVERSE substudy, the NYHA class I patients showed a trend toward worsened HF clinical composite response [33]. One can say, symptom severity correlates poorly with many measures of LV function; however, there are some papers supporting our assumption [34].

Similarly, QRS complex reflects the continuity of disease progression. Too healthy subjects, with narrow QRS do not respond to CRT. IVCD is associated with greater scar burden than LBBB in ischemic cardiomyopathy [35]. Patients with non-LBBB pattern show significantly less benefit from CRT than those with LBBB [36]. It seems that the perfect CRT candidate seems to be neither too sick nor healthy.

Our study also presents data of the long-term follow-up. We revealed that CRT response defined as $\triangle \mathrm{LVESV}>15 \%$ was positive survival prognostic factor. This is in accordance with the other studies [37, 38]. On the other hand, being peripheral/mid-range LVGLS influenced $\triangle$ LVESV. Therefore, we may suspect that the peripheral/mid-range LVGLS may also contribute in long term survival. Further studies with increased number of patients are necessary to confirm this hypothesis.

\section{Limitations}

Small and heterogeneous sample is the most important limitation of the study. Study was not randomized. The quality of echocardiographic images is crucial for strain analysis; therefore, sometimes the image quality may be suboptimal. Post-implantation CRT optimization was not taken into consideration. Dyssynchrony analysis was performed but the results were not decisive and no single parameter was able to predict CRT response. Therefore, these results were not shown and we concentrated on the main aim of the study.

\section{Conclusions}

Cardiac resynchronization therapy has a positive effect on overall outcome in HFrEF patients expressed as LV reverse remodeling. Baseline LVGLS may be an important marker in predicting response to CRT with the relationship of inverted J-shaped curve pattern. Patients with intermediate LVGLS values are more likely to respond positively to CRT, especially in non-ischemic etiology of HF.

Author contributions Conceptualization: KM-S. Methodology: WW, DU-S. Formal analysis and investigation: WW, AB-K, AF, writingoriginal draft preparation: WO. Writing - review and editing: KM-S, WO, WK. Funding acquisition: KM-S. Supervision: KM-S.

Funding Grant for scientific research in the field of CRT efficacy funded by Medical University of Silesia.

\section{Compliance with ethical standards}

Conflict of interest The authors declare that they have no conflict of interest.

Open Access This article is licensed under a Creative Commons Attribution 4.0 International License, which permits use, sharing, adaptation, distribution and reproduction in any medium or format, as long as you give appropriate credit to the original author(s) and the source, provide a link to the Creative Commons licence, and indicate if changes were made. The images or other third party material in this article are included in the article's Creative Commons licence, unless indicated otherwise in a credit line to the material. If material is not included in the article's Creative Commons licence and your intended use is not permitted by statutory regulation or exceeds the permitted use, you will need to obtain permission directly from the copyright holder. To view a copy of this licence, visit http://creativecommons.org/licenses/by/4.0/. 


\section{References}

1. Moss AJ, Hall WJ, Cannom DS, Klein H, Brown MW, Daubert JP, Estes NAM, Foster E, Greenberg H, Higgins SL, Pfeffer MA, Solomon SD, Wilber D, Zareba W (2009) Cardiac-resynchronization therapy for the prevention of heart-failure events. N Engl J Med 361:1329-1338

2. Bristow MR, Saxon LA, Boehmer J, Krueger S, Kass DA, De Marco T, Carson P, DiCarlo L, DeMets D, White BG, DeVries DW, Feldman AM (2004) Comparison of medical therapy, pacing, and defibrillation in heart failure (COMPANION) investigators. Cardiac-resynchronization therapy with or without an implantable defibrillator in advanced chronic heart failure. N Engl J Med 350:2140-2150

3. Zhang Q, Zhou Y, Yu C-M (2015) Incidence, definition, diagnosis, and management of the cardiac resynchronization therapy nonresponder. Curr Opin Cardiol 30:40-49

4. Chung ES, Leon AR, Tavazzi L, Sun J-P, Nihoyannopoulos P, Merlino J, Abraham WT, Ghio S, Leclercq C, Bax JJ, Yu C-M, Gorcsan J, St John Sutton M, De Sutter J, Murillo J (2008) Results of the predictors of response to CRT (PROSPECT) trial. Circulation 117:2608-2616

5. Brown J, Jenkins C, Marwick TH (2009) Use of myocardial strain to assess global left ventricular function: a comparison with cardiac magnetic resonance and 3-dimensional echocardiography. Am Heart J 157:102.e1-5

6. Marwick TH (2006) Measurement of strain and strain rate by echocardiography: ready for prime time? J Am Coll Cardiol 47:1313-1327

7. Szymczyk E, Lipiec P, Michalski B, Kasprzak JD (2013) 2D and 3D speckle tracking echocardiography: clinical application. Kardiol Pol 71:77-83

8. Roes SD, Mollema SA, Lamb HJ, van der Wall EE, de Roos A, Bax JJ (2009) Validation of echocardiographic two-dimensional speckle tracking longitudinal strain imaging for viability assessment in patients with chronic ischemic left ventricular dysfunction and comparison with contrast-enhanced magnetic resonance imaging. Am J Cardiol 104:312-317

9. Suffoletto MS, Dohi K, Cannesson M, Saba S, Gorcsan J (2006) Novel speckle-tracking radial strain from routine black-andwhite echocardiographic images to quantify dyssynchrony and predict response to cardiac resynchronization therapy. Circulation 113:960-968

10. Biering-Sørensen T, Biering-Sørensen SR, Olsen FJ, Sengeløv M, Jørgensen PG, Mogelvang R, Shah AM, Jensen JS (2017) Global longitudinal strain by echocardiography predicts long-term risk of cardiovascular morbidity and mortality in a low-risk general population CLINICAL PERSPECTIVE. Circ Cardiovasc Imaging 10:e005521

11. Bax JJ, Delgado V, Sogaard P, Singh JP, Abraham WT, Borer JS, Dickstein K, Gras D, Brugada J, Robertson M, Ford I, Krum H, Holzmeister J, Ruschitzka F, Gorcsan J (2017) Prognostic implications of left ventricular global longitudinal strain in heart failure patients with narrow QRS complex treated with cardiac resynchronization therapy: a subanalysis of the randomized EchoCRT trial. Eur Heart J 38:720-726

12. Pouleur A-C, Knappe D, Shah AM, Uno H, Bourgoun M, Foster E, McNitt S, Hall WJ, Zareba W, Goldenberg I, Moss AJ, Pfeffer MA, Solomon SD (2011) MADIT-CRT investigators. Relationship between improvement in left ventricular dyssynchrony and contractile function and clinical outcome with cardiac resynchronization therapy: the MADIT-CRT trial. Eur Heart J 32:1720-1729

13. Castel A-L, Szymanski C, Delelis F, Levy F, Menet A, Mailliet A, Marotte N, Graux P, Tribouilloy C, Maréchaux S (2014)
Prospective comparison of speckle tracking longitudinal bidimensional strain between two vendors. Arch Cardiovasc Dis 107:96-104

14. Barbier $P$, Mirea $O$, Cefalù $C$, Maltagliati $A$, Savioli $G$, Guglielmo M (2015) Reliability and feasibility of longitudinal AFI global and segmental strain compared with $2 \mathrm{D}$ left ventricular volumes and ejection fraction: intra- and inter-operator, test-retest, and intercycle reproducibility. Eur Heart J Cardiovasc Imaging 16:642-652

15. Brignole M, Auricchio A, Baron-Esquivias G, Bordachar P, Boriani G, Breithardt O-A, Cleland J, Deharo J-C, Delgado V, Elliott PM, Gorenek B, Israel CW, Leclercq C, Linde C, Mont L, Padeletti L, Sutton R, Vardas PE, Zamorano JL, Achenbach S, Baumgartner H, Bax JJ, Bueno H, Dean V, Deaton C, Erol C, Fagard R, Ferrari R, Hasdai D, Hoes AW, Kirchhof P, Knuuti J, Kolh P, Lancellotti P, Linhart A, Nihoyannopoulos P, Piepoli MF, Ponikowski P, Sirnes PA, Tamargo JL, Tendera M, Torbicki A, Wijns W, Windecker S, Kirchhof P, Blomstrom-Lundqvist C, Badano LP, Aliyev F, Bansch D, Baumgartner H, Bsata W, Buser P, Charron P, Daubert J-C, Dobreanu D, Faerestrand S, Hasdai D, Hoes AW, Le Heuzey J-Y, Mavrakis H, McDonagh T, Merino JL, Nawar MM, Nielsen JC, Pieske B, Poposka L, Ruschitzka F, Tendera M, Van Gelder IC, Wilson CM (2013) ESC Guidelines on cardiac pacing and cardiac resynchronization therapy: the Task Force on cardiac pacing and resynchronization therapy of the European Society of Cardiology (ESC). Developed in collaboration with the European Heart Rhythm Association. Europace 15:1070-1118

16. Ma C-Y, Liu S, Yang J, Tang L, Zhang L-M, Li N, Yu B (2014) Evaluation of global longitudinal strain of left ventricle and regional longitudinal strain in the region of left ventricular leads predicts the response to cardiac resynchronization therapy in patients with ischemic heart failure. Cell Biochem Biophys 70:143-148

17. Delgado-Montero A, Tayal B, Goda A, Ryo K, Marek JJ, Sugahara M, Qi Z, Althouse AD, Saba S, Schwartzman D, Gorcsan J (2016) Additive prognostic value of echocardiographic global longitudinal and global circumferential strain to electrocardiographic criteria in patients with heart failure undergoing cardiac resynchronization TherapyCLINICAL PERSPECTIVE. Circ Cardiovasc Imaging 9:e004241

18. Hasselberg NE, Haugaa KH, Bernard A, Ribe MP, Kongsgaard E, Donal E, Edvardsen T (2016) Left ventricular markers of mortality and ventricular arrhythmias in heart failure patients with cardiac resynchronization therapy. Eur Heart J Cardiovasc Imaging 17:343-350

19. Gorcsan J, Anderson CP, Tayal B, Sugahara M, Walmsley J, Randall CS, Lumens J (2019) Systolic stretch characterizes the electromechanical substrate responsive to cardiac resynchronization therapy. JACC Cardiovasc Imaging 12(9):1741-1752

20. Onishi T, Saha SK, Delgado-Montero A, Ludwig DR, Onishi T, Schelbert EB, Schwartzman D, Gorcsan J (2015) Global longitudinal strain and global circumferential strain by speckle-tracking echocardiography and feature-tracking cardiac magnetic resonance imaging: comparison with left ventricular ejection fraction. J Am Soc Echocardiogr 28:587-596

21. Menet A, Guyomar Y, Ennezat P-V, Graux P, Castel AL, Delelis F, Heuls S, Cuvelier E, Gevaert C, Le Goffic C, Tribouilloy C, Maréchaux S (2016) Prognostic value of left ventricular reverse remodeling and performance improvement after cardiac resynchronization therapy: a prospective study. Int J Cardiol 204:6-11

22. Khidir MJH, Abou R, Yilmaz D, Ajmone Marsan N, Delgado V, Bax JJ (2018) Prognostic value of global longitudinal strain in heart failure patients treated with cardiac resynchronization therapy. Hear Rhythm 15:1533-1539

23. Kydd AC, Khan FZ, Ring L, Pugh PJ, Virdee MS, Dutka DP (2014) Development of a multiparametric score to predict left 
ventricular remodelling and prognosis after cardiac resynchronization therapy. Eur J Heart Fail 16:1206-1213

24. Park J-H, Negishi K, Grimm RA, Popovic Z, Stanton T, Wilkoff BL, Marwick TH (2013) Echocardiographic predictors of reverse remodeling after cardiac resynchronization therapy and subsequent events. Circ Cardiovasc Imaging 6:864-872

25. Sassone B, Gambetti S, Bertini M, Beltrami M, Mascioli G, Bressan S, Fucà G, Pacchioni F, Pedaci M, Michelotti F, Bacchi Reggiani ML, Padeletti L (2015) Relation of QRS duration to response to cardiac resynchronization therapy. Am J Cardiol 115:214-219

26. Bax JJ, Bleeker GB, Marwick TH, Molhoek SG, Boersma E, Steendijk P, van der Wall EE, Schalij MJ (2004) Left ventricular dyssynchrony predicts response and prognosis after cardiac resynchronization therapy. J Am Coll Cardiol 44:1834-1840

27. Risum N, Jons C, Olsen NT, Fritz-Hansen T, Bruun NE, Hojgaard MV, Valeur N, Kronborg MB, Kisslo J, Sogaard P (2012) Simple regional strain pattern analysis to predict response to cardiac resynchronization therapy: rationale, initial results, and advantages. Am Heart J 163:697-704

28. Ahmed W, Samy W, Tayeh O, Behairy N, Abd El Fattah A (2016) Left ventricular scar impact on left ventricular synchronization parameters and outcomes of cardiac resynchronization therapy. Int J Cardiol 222:665-670

29. Sengupta PP, Korinek J, Belohlavek M, Narula J, Vannan MA, Jahangir A, Khandheria BK (2006) Left ventricular structure and function: basic science for cardiac imaging. J Am Coll Cardiol 48:1988-2001

30. Chinitz JS, d'Avila A, Goldman M, Reddy V, Dukkipati S (2014) Cardiac resynchronization therapy: who benefits? Ann Glob Heal 80:61-68

31. Cimino S, Maestrini V, Cantisani D, Petronilli V, Filomena D, Gatto MC, Birtolo LI, Piro A, Lavalle C, Agati L (2019) 2D/3D Echocardiographic features of patients with reverse remodeling after cardiac resynchronization therapy. Echocardiography 36:1475-1481

32. Linde C, Gold MR, Abraham WT, St John Sutton M, Ghio S, Cerkvenik J, Daubert C (2013) Long-term impact of cardiac resynchronization therapy in mild heart failure: 5-year results from the REsynchronization reVErses Remodeling in Systolic left vEntricular dysfunction (REVERSE) study. Eur Heart J 34:2592-2599

33. Daubert C, Gold MR, Abraham WT, Ghio S, Hassager C, Goode G, Szili-Török T, Linde C (2009) Prevention of disease progression by cardiac resynchronization therapy in patients with asymptomatic or mildly symptomatic left ventricular dysfunction. J Am Coll Cardiol 54:1837-1846

34. Rangel I, Gonçalves A, de Sousa C, Almeida PB, Rodrigues J, Macedo F, Silva Cardoso J, Maciel MJ (2014) Global longitudinal strain as a potential prognostic marker in patients with chronic heart failure and systolic dysfunction. Rev Port Cardiol 33:403-409

35. Adelstein EC, Althouse AD, Schwartzman D, Jain SK, Soman P, Saba S (2018) Scar burden, not intraventricular conduction delay pattern, is associated with outcomes in ischemic cardiomyopathy patients receiving cardiac resynchronization therapy. Heart Rhythm 15:1664-1672

36. Domenichini G, Burri H, Valzania C, Gavaruzzi G, Fallani F, Biffi M, Sunthorn H, Diemberger I, Martignani C, Foulkes H, Fleury E, Boriani G (2012) QRS pattern and improvement in right and left ventricular function after cardiac resynchronization therapy: a radionuclide study. BMC Cardiovasc Disord 12:27

37. Sugano A, Seo Y, Yamamoto M, Harimura Y, Machino-Ohtsuka T, Ishizu T, Aonuma K (2017) Optimal cut-off value of reverse remodeling to predict long-term outcome after cardiac resynchronization therapy in patients with ischemic cardiomyopathy. J Cardiol 69:456-461

38. Toniolo M, Zanotto G, Rossi A, Tomasi L, Prioli MA, Vassanelli C (2013) Long-term independent predictors of positive response to cardiac resynchronization therapy. J Cardiovasc Med (Hagerstown) 14:301-307

Publisher's Note Springer Nature remains neutral with regard to jurisdictional claims in published maps and institutional affiliations. 